J. Clin. Chem. Clin. Biochem.

Vol. 20, 1982, pp. 899-905

\title{
A Semi-Automated Computerised Gas-Liquid Chromatographic System for Urinary Steroid Profile Analysis
}

\author{
By H. L. J. Makin and D. J. H. Trafford
}

Steroid Laboratory, Department of Chemical Pathology, The London Hospital Medical College, London, UK

Received April 13/July 12, 1982)

\begin{abstract}
Summary: A simple gas-liquid chromatographic method for the measurement of some of the major steroids in urine is described. The system uses conventional packed columns, automatic injection and is linked to an integrator. Calculations are all carried out by computer. The system is recommended as a simple screening procedure, producing a urinary steroid 'profile', which can process large numbers of urine samples cheaply and quickly, enabling patients worthy of more intensive investigation to be identified.
\end{abstract}

Ein halbautomatisiertes, Rechner-gestütztes gaschromatographisches System zur Analyse von Steroid-Profilen im Harn

Zusammenfassung: Eine einfache gaschromatographische Methode zur Messung einiger der wichtigsten Steroide im Harn wird beschrieben. Das System verwendet konventionelle gepackte Säulen, automatische Injektion und ist mit einem Integrator gekoppelt. Alle Berechnungen werden von einem Rechner ausgeführt. Das System wird als einfaches Screening-Verfahren empfohlen und ergibt ein „Steroid-Profil“ des Harns. Das Verfahren kann große Zahlen von Harnproben billig und schnell verarbeiten und ermöglicht die Identifizierung von Patienten, die einer intensiveren Untersuchung bedürfen.

\section{Introduction}

The measurement of urinary 17-oxo- and 17:oxogenic steroids is still carried out in many clinical laboratories by manual colorimetric methods (1) and these group analyses provide a useful clinical index of adrenocortical function. Plasma steroid assays require venepunctuire and concentrations obtained indicate the endocrine status at the time of sampling only. Plasma levels of some stereroids ündergo rapid pulsatile changes (2) and thus are liable to considerable error. Urinary steroid excretion on the other hand represents the integrated secretion over the period of urine collection and thus provides an arguably better index of endocrine status. Although accurate $24 \mathrm{~h}$ collections are notoriously difficult to achieve except under laboratory conditions, urine collection is non-invasive, which is of particular significance in young children, and steroid: creatinine ratios have been used in attempts to overcome the difficulties of collection.

Despite the advantages of urine steroid assays they have largely been supplanted by the advent of radioimmunoassays for plasma steroids. But there would still seem to be a place for urinary steroid analysis - particularly for multi-component or "profile" analysis $(3,4)$.

Shackleton (4) advocates the use of a capillary gas-liquid chromatographic system (5) for this purpose, using SepPak cartridges for extraction and suggests that such a system is within the capabilities of many clinical laboratories.

Capillary column GLC ist not easy to operate or interpret and, in our view, should not be regarded as a routine system for the analysis of urinary steroids, although it is however a very valuable technique and certainly has a place in the detailed investigation and characterisation of those patients shown to have endocrine abnormalities, such as congenital adrenal hyperplasia (6) or placental sulphatase deficiency (7). We would advocate the prior use of a simpler screening procedure which can process large numbers of samples more quickly and cheaply than is possible using capillary GLC, allowing the detection of those patients in whom a more exacting examination, such as that described by Shackleton (4), is required. To that end we describe here a semi-automated computerised gas-liquid chromatographic system, using conventional packed columns. 
This system has been in routine use at the London Hospital for nearly 10 years as a screening procedure for the investigation of patients with suspected adrenocortical dysfunction. This procedure measures the major 17-oxo-, 17-oxogenic and other major steroid metabolites present in human urine.

\section{Materials and Methods}

\section{Reagents}

Reagents used were all Analytical Reagent grade from BDH Chemicals Ltd. Poole, Dorset, UK if available - otherwise the highest grade reagent was obtained and purified by distillation prior to use. Methylene chloride was tested before use by evaporating $50 \mathrm{ml}$ to dryness and chromatographing $1 / 20$ th of the final extract, examining for the presence of dibutyl or dioctyl phthalates - the latter has the same retention time as aetiocholanolane formate in the GLC system used. Batches of methylene chloride with high concentrations of phthalates present were returned to the suppliers or redistilled before use. Other reagents used were as described by Trafford \& Makin (8).

Steroid formate esters are particularly susceptible to absorption and/or destruction on the 'inert' support of the stationary phase (9). Most commercially available supports were found to vary considerably and were seldom adequate for use with steroid formates. Column packing materials were therefore prepared by coating inactivated Celite 545 (100/200 mesh, Phase Separations Ltd., Queensferry, Flintshire, UK) with $1-2 \%$ OV1 (Phase Separations Ltd.) by treating $50 \mathrm{~g}$ of inactivated Celite 545 with $100 \mathrm{ml}$ of $1-2 \%$ solution of OV1 in toluene, using the filtration method described by Supina (10).

Celite was inactivated by standing for 7 days in $50 \%$ ( $v / v$ ) concentrated hydrochloric acid and then washed to neutrality with distilled water, discarding fines at each wash. After drying in a vacuum oven for $48 \mathrm{~h}$ at $37^{\circ} \mathrm{C}$, the Celite was flushed with oxygen-free nitrogen for 24 hours. After this period, dimethyldichlorosilane solution ( $10 \mathrm{ml} / 1$ in toluene) was added, the slurry degassed and filled with nitrogen. After 1 hour, the di- methyldichlorosilane solution was removed using a Büchner filter, and the Celite re-suspended in methanol three times and finally dried at $37^{\circ} \mathrm{C}$ in a vacuum oven for 24 hours. Only if this procedure was carefully followed was consistent quality packing material obtained. A crucial step was found to be the rigorous exclusion of oxygen prior to and during the 'silanisation' procedure. GLC columns were theminselves 'silanised' by treatment with $10 \mathrm{ml} / 1$ dimethyldichlorosilane, in toluene, washed with methanol and dried prior to filling with the packing material (approx. $7 \mathrm{~g}$ per column, $2.1 \mathrm{~m} \times 0.4 \mathrm{~cm}$ ID). Each column was connected to the carrier gas (nitrogen) at room temperature and the column gassed for $10 \mathrm{~min}$ to exclude oxygen. The column was then heated with no carrier gas flow for 1 hour at $300^{\circ} \mathrm{C}$. After cooling the carrier gas flow was resumed and the column conditioned by heating for 12 hours at its maximum operating temperature. Columns were tested before use by injecting $0.1 \mu \mathrm{l}$ and $1.0 \mu \mathrm{l}$ of a mixture of standard steroid formates. The response factors of each component of the mixture in relation to the internal standards should be the same whatever volume is injected. Table 1 gives a list of the steroid used in this standard mix ture together with the typical response factors obtained on a satisfactory column. $11 \beta$-hydroxyaetiocholanolone formate, having a sterically hindered, and thus unesterified, $11 \beta$-hydroxyl, is particularly susceptible to absorption. Figure 1 indicates the variation of the response factor for $11 \beta=$ hydroxyaetiocholanolone with volume injected using an unsatisfactory column showing absorption and a satisfactory column. Columns which have been in use for some time begin to show selective absorption of 11-hydroxy steroids which can occasionally be overcome in the short-term by the injection of water. However the best solution is either to replace the column or to re-pack the first $10 \mathrm{~cm}$ of column packing with fresh material.

\section{Method}

The chemical procedures used prior to GLC analysis were generally as described by Trafford \& Makin (8) and are outlined in table 2 except that sodium metaperiodate oxidation was carried out in $0.1 \mathrm{~mol} / 1$ phosphate buffer, $\mathrm{pH} 6.0$ and methylene dichloride extracts were washed with $5 \%(\mathrm{v} / \mathrm{v})$ hydrochloric acid after the $\mathrm{NaOH}$ wash. This extra wash was found to be necessary to remove basic drug metabolites which occasionally interfered in the GLC analysis - for example propranolol (8) and trimethoprim (a component of Septrin). Extraction with methylene

Tab. 1. Composition of a typical standard steroid formate mix ture.

\begin{tabular}{|c|c|c|c|c|}
\hline Steroid formate & $\begin{array}{l}\text { Urinary steroid metabolite } \\
\text { from which formate ester in } \\
\text { extract might be derived }\end{array}$ & $\begin{array}{l}\text { Mass of } \\
\text { each steroid } \\
(\mu g) \text { in } \\
\text { standard } \\
\left.\text { mixture }{ }^{1}\right)\end{array}$ & \multicolumn{2}{|c|}{ Typical value for } \\
\hline $5 \alpha$-Androstan-17-one (standard 1) & internal standard & 16.7 & 0.2398 & 1.00 \\
\hline 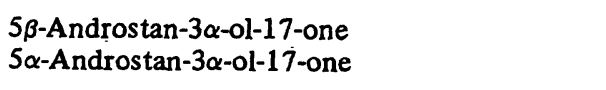 & $\begin{array}{l}\text { cortisol precursor } \\
\text { metabọlites }\end{array}$ & $\begin{array}{l}31.1 \\
35.0\end{array}$ & $\begin{array}{l}0.4639 \\
0.5103\end{array}$ & $\begin{array}{l}1.14 \\
1.14\end{array}$ \\
\hline $\begin{array}{l}5 \beta \text {-Androstane- } 3 \alpha, 17 \alpha \text {-diol } \\
5 \beta \text {-Androstane- } 3 \alpha, 17 \alpha \text {-diol }\end{array}$ & $\begin{array}{l}\text { aetiocholanolone } \\
\text { androsterone }\end{array}$ & $\begin{array}{l}31.3 \\
32.7\end{array}$ & $\begin{array}{l}0.5654 \\
0.6138\end{array}$ & $\begin{array}{l}0.91 \\
0.91\end{array}$ \\
\hline $\begin{array}{l}5 \beta \text {-Andróstane-3 } \alpha, 11 \beta \text {-diol-17-one } \\
5 \alpha \text {-Androstane-3 } \alpha, 11 \beta \text {-diol-17-one }\end{array}$ & $\begin{array}{l}\text { cortisol } \\
\text { metabolites }\end{array}$ & $\begin{array}{l}53.0 \\
39.3\end{array}$ & $\begin{array}{r}0.6704 \\
.0 .7415\end{array}$ & $\begin{array}{l}1.34 \\
1.12\end{array}$ \\
\hline $5 \beta$-Pregane-3 $\alpha, 20 \alpha$-diol diacetate (standard 2) & internal standard & 66.5 & 1.0000 & 1.00 \\
\hline Cholesterol & cholesterol & 44.0 & 1.3443 & $0: 92$ \\
\hline 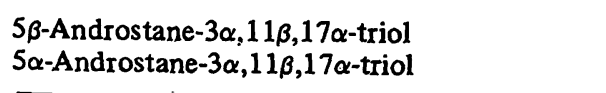 & $\begin{array}{l}\text { 11-oxygenated } \\
\text { androgens }\end{array}$ & $\begin{array}{l}0 \\
0\end{array}$ & $\begin{array}{l}0.7979 \\
0.8753\end{array}$ & $\begin{array}{l}\left.1.344^{4}\right) \\
\left.1.12^{4}\right)\end{array}$ \\
\hline
\end{tabular}

1) expressed as mass of unesterified steroid.

2) RRT; retention time relative to that of standard 2 (retention times of standard 1 and standard 2 are usually around 478 and 2000 s).

3) RF: FID response factor (see text for details).

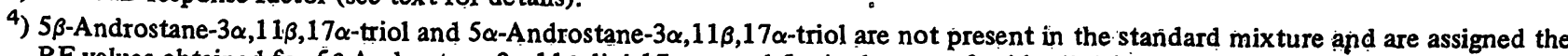

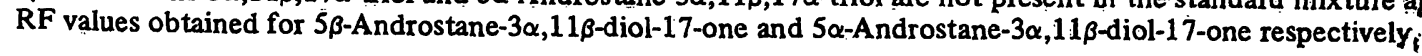




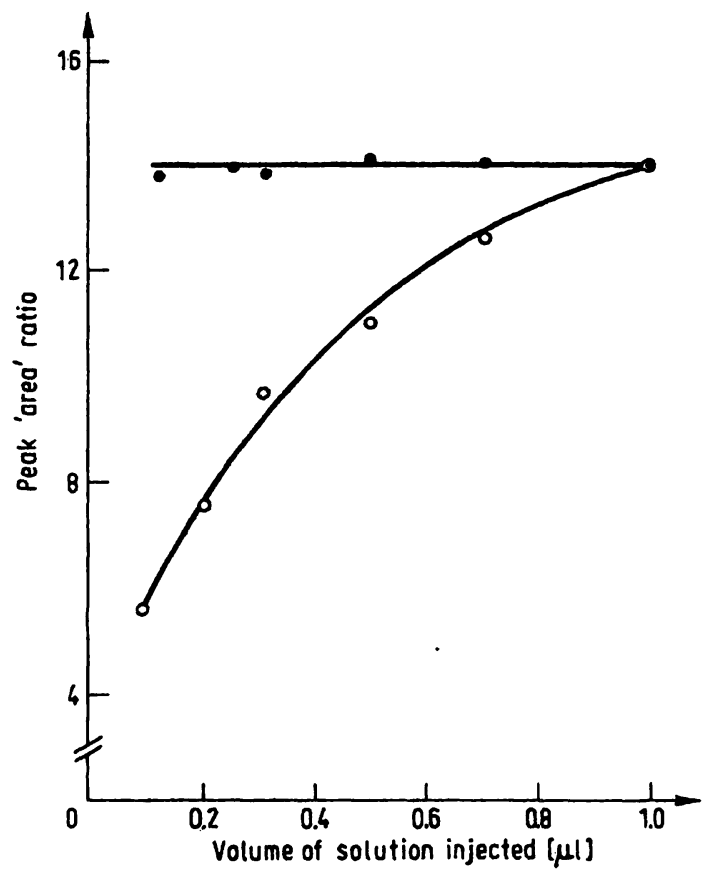

Fig. 1. Effect of injecting standard steroid formate mixture on GLC columns packed with differing support (satisfactory - - , no absorption; unsatisfactory $0-0$, showing absorption) material. Decreasing volumes of a standard steroid solution (see table 1 for composition) were injected onto the columns, and peak 'area' ratios (i.e. 'area' of 11 $\beta$-hydroxyaetiocholanolone / 'area' of standard 1) were measured (for details see 1.c. (8)).

chloride was carried out on an automatic shaker for at least 5 minutes, since investigations showed that a short period of shaking did not extract all steroids to the same degree - an example of this is illustrated in figure 2.In addition care has to be taken when evaporating solvents under nitrogen flow at $37^{\circ} \mathrm{C}$ since some steroids (notably $5 \alpha$-androstan-17-one, used as one of the internal standards) are slightly volatile and excessive incubation, when dry, leads to evaporation of steroid. Only incubation of dried extracts with formic acid vapour has been found to form formate esters quarititatively without destruction on all non-sterically hindered groups so far studied. Figure 3 shows the esterification of the 3-hydroxyl group of aetiocholanolone and $11 \beta$-hydroxyaetiocholanolone.

Tab. 2. An outline of the manual chemistry prior to gas-liquid chromatography.

1. Reduction of oxo groups to corresponding alcohols with sodium borohydride $\left(15\right.$ min at $\left.50^{\circ} \mathrm{C}\right)$.

2. Destruction of excess borohydride with acid $(250 \mathrm{ml} / \mathrm{l}$ acetic acid, $15 \mathrm{~min}$ at $50^{\circ} \mathrm{C}$ ).

3. Side-chain cleavage and glucuronide hydrolysis with sodium metaperiodate at $\mathrm{pH} 6.0\left(15 \mathrm{~min}\right.$ at $\left.50^{\circ} \mathrm{C}\right)$.

4. Extraction of liberated steroids with methylene dichloride (at least 2 min shaking).

5. Esterification of dried residues with formic acid vapour at $80^{\circ} \mathrm{C}$ (at least $1 \mathrm{~h}$ ).

Time for processing (in batches of 12 samples): $2.5 \mathrm{~h}$. Since oxo groups are reduced and side chains removed by this chemistry, information about the original metabolites can be lost (i.e. it does not distinguish between $5 \beta$ pregnanetriol and $5 \beta$-tetrahydro Reichenstein $S$ as precursors of aetiocholanolone formate).

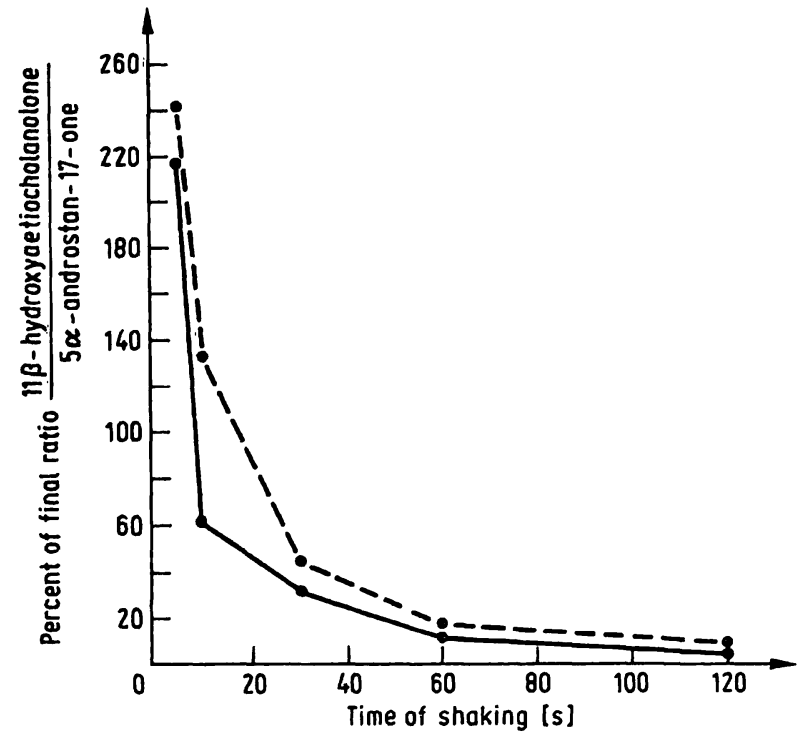

Fig. 2. Extraction of steroids from aqeuous $\left(\bullet-\bullet \mathrm{H}_{2} \mathrm{O}\right.$, $\bullet-\bullet$ urine) media. Steroids present in urine after borohydride reduction and periodate oxidation (as described in the text) were extracted with dichloromethane for varying times, after addition of an internal standard ( $5 \alpha$-androstan17-one). The extracts were evaporated to dryness, esterified with formic acid and analysed by GLC. Water, to which a mixture of $11 \beta$-hydroxyaetiocholanolone and $5 \alpha$-androstan-17-one) had been added, was similarly treated. The change in the ratio $11 \beta$-hydroxyaetiocholanolone/ $5 \alpha$-androstan-17-one is expressed as a percentage of the final ratio.

Gas-liquid chromatography was carried out using an F 30 gas chromatograph and flame ionisation detection, injecting samples using an AS 41 injection system (Perkin-Elmer Ltd., Beaconsfield, Bucks., UK). This injection system, which has a capacity of up to 100 samples uses small aluminium capsules into which the sample is.loaded (maximum sample volume is around $20 \mu 1)$. The capsules are sealed by cold-welding and loaded in numbered racks, each containing 10 capsules. Capsules are injected one after the other according to the programme

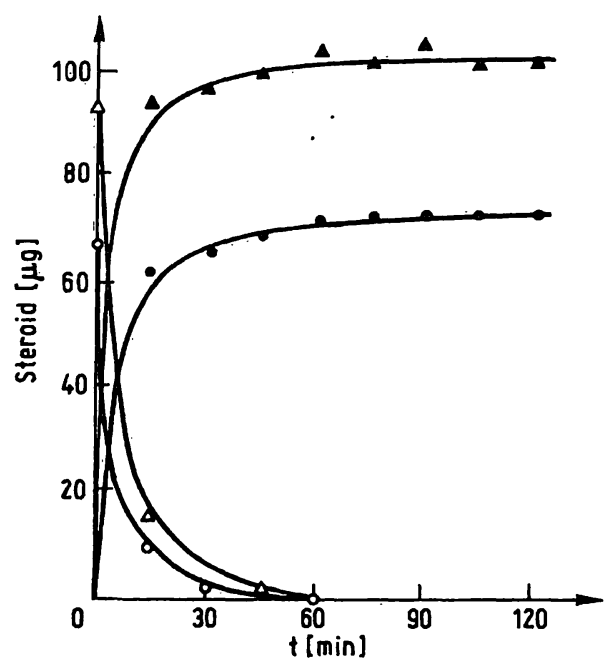

Fig. 3. Rate of esterification of $11 \beta$-hydroxyaetiocholanolone and aetiocholanolone by formic acid vapour at $80^{\circ} \mathrm{C}$ as described by Trafford \& Makin (7).

Aetiocholanolone: unesterified, $0-0$, esterified, $\bullet-\bullet$. 11 $\beta$-Hydroxyaetiocholanolone: unesterified, $\Delta-\Delta$; esterified, $\triangle \longrightarrow \wedge$. 


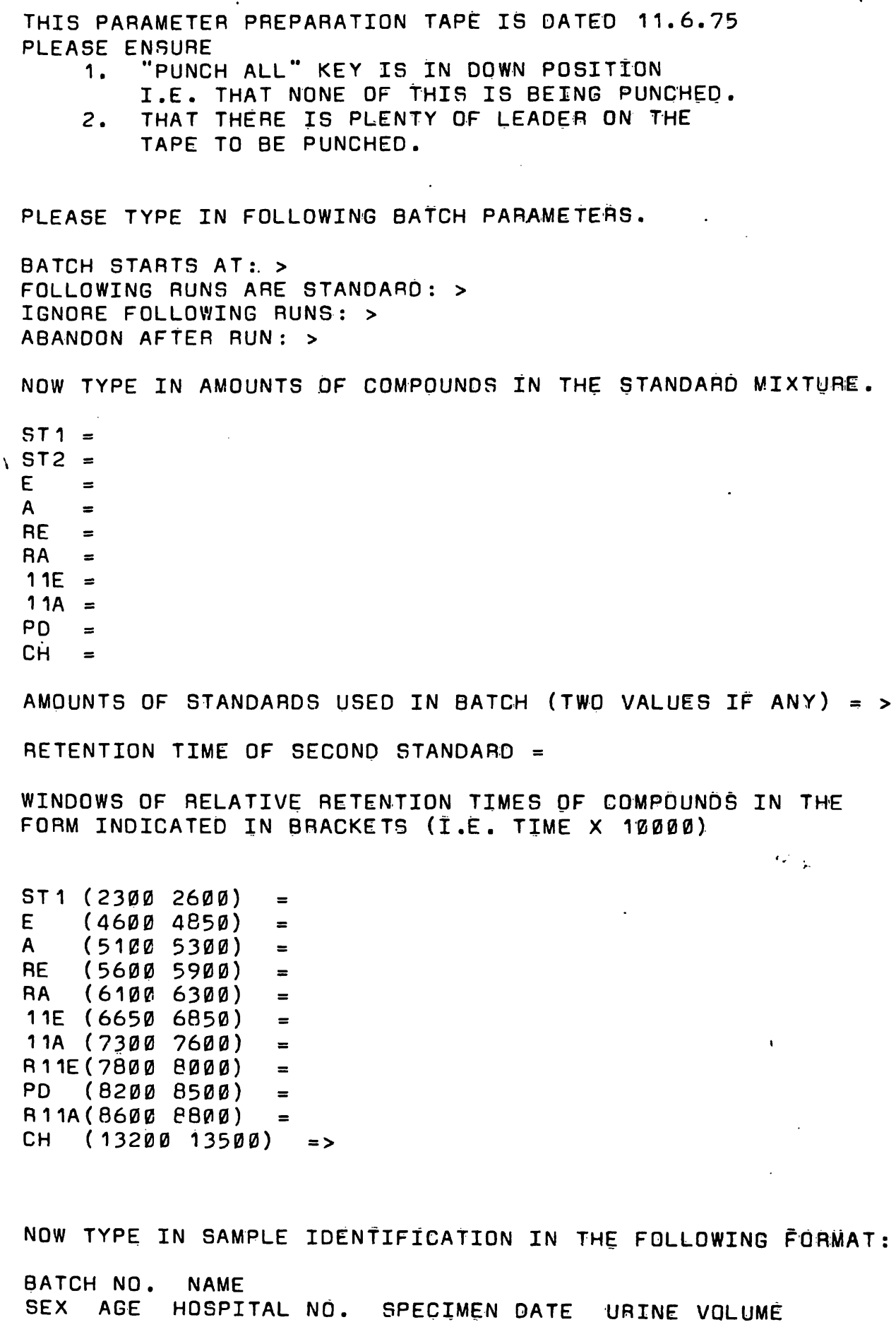
Fig. 4. Information required to generate PARAMETER tape. The questions given here are not punched on the tape which only
records the answers. 
selected. In the system chosen, GLC was carried out with nitrogen flow rate of about $40 \mathrm{ml} / \mathrm{min}$, usually with a starting temperature of around $215^{\circ} \mathrm{C}$ rising at $1^{\circ} \mathrm{C} / \mathrm{min}$ to a maximum at $265^{\circ} \mathrm{C}$. Since different batches of column packing material varied slightly, these temperature settings had to be changed from time to time in order to obtain a retention time for $5 \alpha$-androstan-17-one of approximately $480 \mathrm{~s}$. However each run took 50 minutes, rising at $1{ }^{\circ} \mathrm{C} / \mathrm{min}$ from minimum to maximum temperature settings. The AS41 automatic injection system has the considerable advantage that the whole sample in each capsule is not injected onto the column, thus prolonging column life. Using this injection system, columns need replacing on average after 1 year of continuous use. Each capsule is pierced by a hollow needle, through which pre-heated carrier gas passes, and volatile contents of the capsule are flushed on to the column, leaving the non-volatile components, which usually collect on the top of the column, behind in the capsule, which is then rejected. The FID amplifier output was connected to an Autolab system IV digital integrator (Spectra-Physics Ltd., St. Albans, Herts, UK), although, of course, any comparable integrator would be suitable. The output from the in tegrator was recorded on a teletype (Olivetti type $\mathrm{Te} 300$, British Olivetti Ltd., London W1. UK) and on 8 hole ASCII punched type (the DATA tape). In a given batch of analyses, the first injection was a mix ture of standards, the composition of which is given in table 1, in order to establish the FID response factors for the next four urine extracts, after which another standard was injected and response factors updated for the next four urine extracts. This sequence of standards and urine extracts was followed throughout the batch. When the batch was complete, another tape, the PARAMETER tape, was generated by hand in answer to specific questions, given in figure 4 , which enables the computer to identify standards, urine extracts and other details required to produce a printout of each patient's results ready for reporting to the consultant who requested the analysis. This second tape, apart from giving details of patient identification, also gives retention time windows which are required for peak identification. Figure 5 outlines the system described above.

An outline of the computer calculations used is given in figure 6 . These calculations are relatively simple and can obviously be carried out on simple microprocessors which could be installed in the laboratory. The system described here is one approach to the problem, which was designed to fit within the constraints of the local situation at the London Hospital. Obviously the solution adopted here should not be regarded as ideal and those with access to better computer systems could adapt and improve the principle described here.

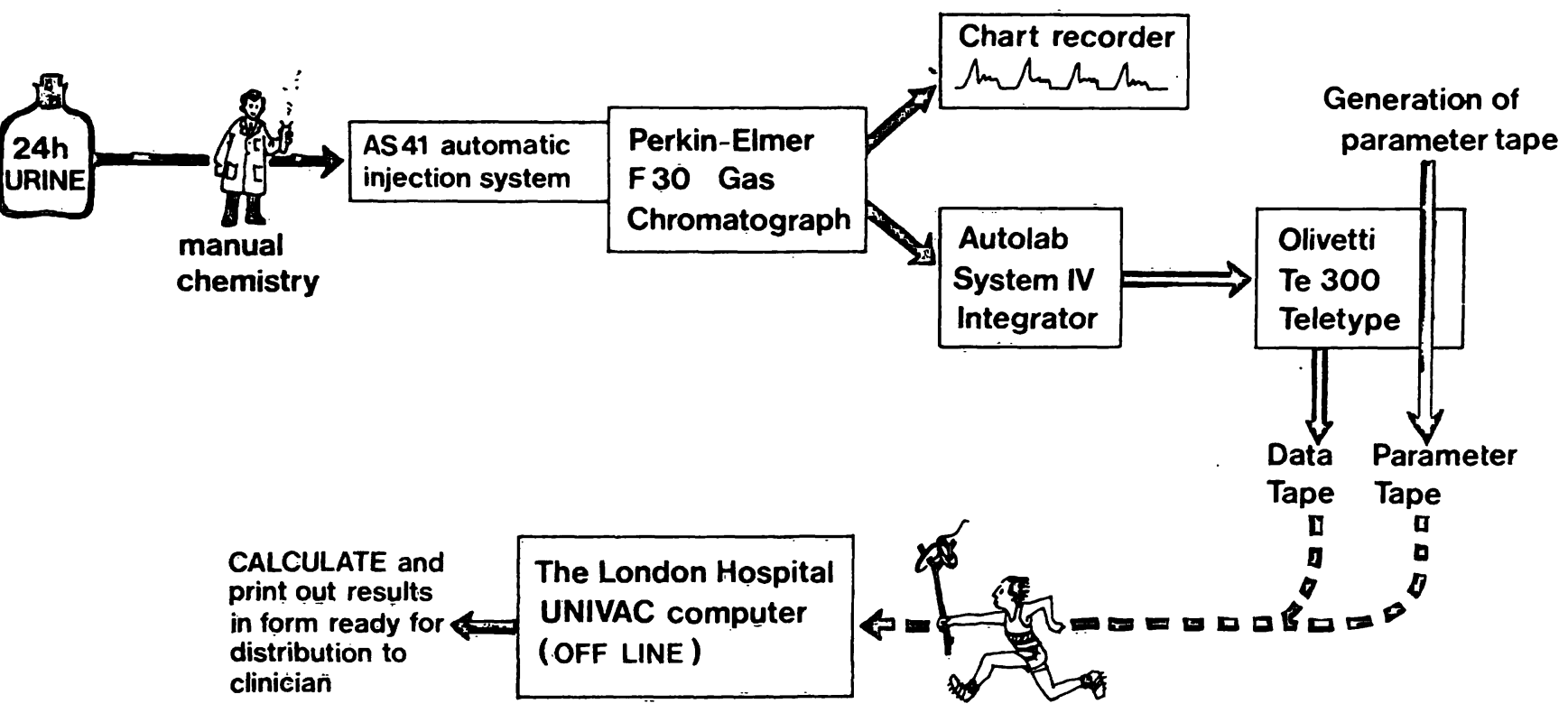

Fig. 5. A schematic outline of the complete 'profiling' system.

\section{Results and Discussion}

The system described here has now been in routine operation at the London Hospital for nearly ten years and has replaced other urinary steroid assays usually requested, 17-oxoṣteroids, 17-oxogenic steroids, pregnanediol, pregnanetriol, 11 oxygenation index, etc., all of which are now provided in a single assay. This system is now offered as a service in the North East Thames Region and for the last five years has been used routinely by St. Bartholomew's Hospital. No special problems have been encountered and it has coped very successfully with the role assigned to it a simple and rapid screening procedure, enabling the identification of patients worthy of further study. The identification of GLC peaks by their retention times is unreliable and can lead to difficulties. However, apart from the two cases mentioned above, propranolol and trimethoprim, we do not believe that we have misidentified any peak. Scanning peaks in the mass spectrometer has always given the expected mass spectrum. In some cases odd profiles have been encountered, such as the one illustrated in figure 7 , which indicates the presence 


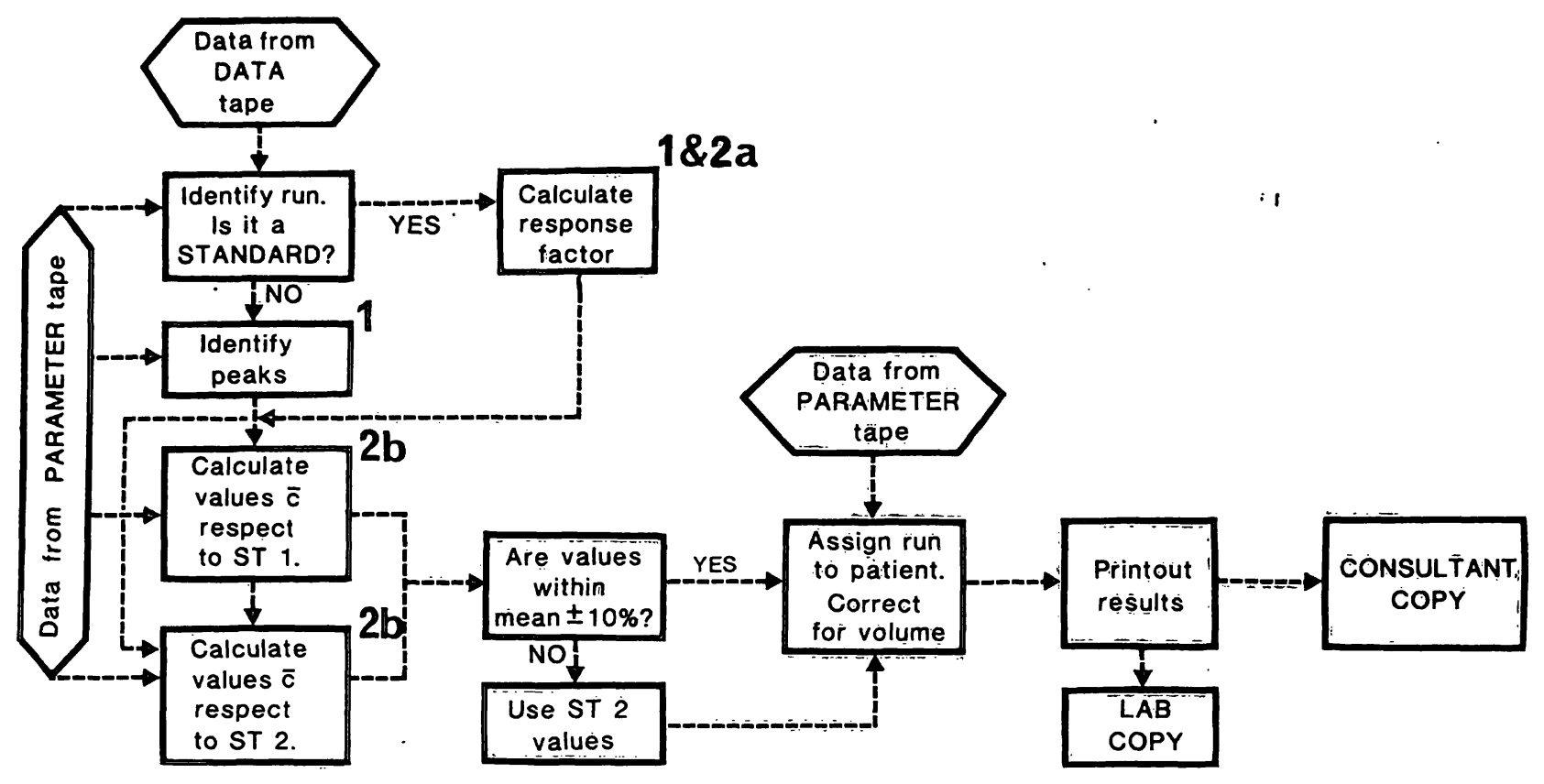

Fig. 6. A schematic 'outline of the computer calculations.

1 Identify standard 2 (standard 2, see table 1) from retention time data givèn on parameter tape (see fig. 6)*; calculate retention times relative to standard 2 (RRT); use these RRT values to identify other peaks - in particular standard 1 (ST1) - from RRT windows on parameter tape; calculate quantity $(Q)$ for each peak using formula:

$Q=\frac{\text { Peak area of steroid }}{\text { Peak area of standard }} \times$ amount of standard

using ST1 and ST2 separately. Mean values are then calculated and used only if values fall within $\pm 10 \%$ of the mean. If outside these limits, values calculated using ST2 are used.

2a If run identified as standard, derive response factors (RF) for each of the identifiable steroids present in the standard mixture (see table 1) from the formula:

$\mathrm{R}=\mathrm{Q} /$ mass of steroid in mixture.

The amount of each steroid in the mixture is given on the parameter tape.

${ }^{2 b}$ If run identified as patient sample, calculate amount of each steroid present (A) from the formula:

$\mathbf{A}=\mathbf{Q} \times \mathbf{R F}$.

In cases where peaks cannot be identified, a response factor of 1.000 is used.

* Since retention time for ST2 changes throughout a batch run, a further test is applied to identify ST2. If there is no peak with the precise retention time, the peak.with the nearest retention time plus the two peaks on either side are üsed. RRTs are calculated using each of the three peaks separately. Using the RRT windows on the parameter tape, other steroids are identified. The peak which allows the identification of the largest number of peaks is taken as ST2. ST2 retention time is updated after every standard run.

of $\mathrm{C}_{20}$-aldehydes, presumably derived by side chain oxidation of tetrahydroreduced metabolites of 11 deoxycorticosterone. During pregnancy, large amounts of $6 \alpha$-hydroxylated progesterone metabolites are excreted in urine, and this GLC system also measures these steroids as well. Figure 8 shows a steroid profile from a woman in the last trimester of pregnancy.

Recoveries of added steroids, normal ranges and reproducibility studies have already been reported by Trafford \&Makin (8) in their study of the manual method and, using this semi-automated procedure, give similar results. Quality control is maintained by running a standard urine sample in every batch - values for precision are given in table 3.

The procedure described here describes an application of gas-liquid chromatography, which illustrates the potenti-
Tab. 3. Reproducibility studies.

\begin{tabular}{|c|c|c|}
\hline (a) Inter-assay $(n=10)$ & $\begin{array}{l}\mathrm{mg} / 24 \mathrm{~h} \\
(\bar{x} \pm s)\end{array}$ & $\begin{array}{l}\mathrm{CV} \\
(\%)\end{array}$ \\
\hline 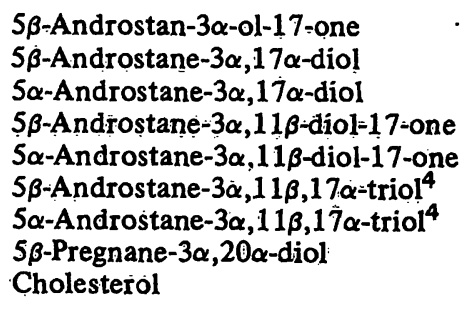 & $\begin{array}{l}1.04 \pm 0.14 \\
1.63 \pm 0.09 \\
2.18 \pm 0.08 \\
7.92 \pm 0.26 \\
1.32 \pm 0.08 \\
0.49 \pm 0.03 \\
0.98 \pm 0.15 \\
0.10 \pm 0.05 \\
0.46 \pm 0.05\end{array}$ & $\begin{array}{r}13.7 \\
5.6 \\
3.6 \\
3.3 \\
6.0 \\
6.4 \\
15.8 \\
50.0 \\
11.2\end{array}$ \\
\hline (b) Intra-assay*) & $\therefore$ & \\
\hline $\begin{array}{l}5 \alpha \text {-Androstane-3 } \alpha, 17 \alpha \text {-diol } \\
5 \beta \text {-Androstane } 3 \alpha, 11 \beta \text {-diol-17-one }\end{array}$ & $\begin{array}{l}2.98 \pm 0.21 \\
5.87 \pm 0.33\end{array}$ & $\begin{array}{l}7: 0 \\
5: 6\end{array}$ \\
\hline
\end{tabular}

*) Sample analysed 20 times over a period of 5 months. Sample stored at $-20^{\circ} \mathrm{C}$. 
. 